\title{
Correction to: Resistance evaluation of differentials and commercial wheat cultivars to stripe rust (Puccinia striiformis) infection in hot spot regions of Canada
}

\author{
Gurcharn Singh Brar • Raman Dhariwal • \\ Harpinder Singh Randhawa
}

Published online: 23 March 2018

C) Koninklijke Nederlandse Planteziektenkundige Vereniging 2018

Correction to: European Journal of Plant Pathology https://doi.org/10.1007/s10658-018-1446-3

Table 2 AAC Penhold is CPSR wheat and carries Yr18 (not CWRS).

Fig. 2 Two-dimensional hierarchical clustering of siteyears and wheat cultivars based on percent severity of stripe rust from natural infection. Colors for each cell represent infection response of a cultivar at given siteyear. Here red $=$ resistant $(\mathrm{R})$, orange $=$ moderately resistant $(\mathrm{MR})$, light blue $=$ moderately resistant to moderately susceptible (MRMS), and dark blue = susceptible (S) infection responses and Cre- Creston, British Columbia; Leth- Lethbridge, Alberta.

The online version of the original article can be found at https://doi.org/10.1007/s10658-018-1446-3

G. S. Brar

Crop Development Centre/Department of Plant Science,

University of Saskatchewan, 51 Campus Dr, Saskatoon, SK S7N

5A8, Canada

R. Dhariwal • H. S. Randhawa $(\square)$

Lethbridge Research and Development Centre, Agriculture and

Agri-Food Canada, 5403-1 Avenue South, Lethbridge, AB T1J

4B1, Canada

e-mail: harpinder.randhawa@agr.gc.ca 